\title{
Microstructure investigation of duplex stainless steel welds using arc heat treatment technique
}

\author{
Andrea Putz $^{1}$ - Vahid A. Hosseini ${ }^{2}$ - Elin M. Westin ${ }^{3} \cdot$ Norbert Enzinger $^{1}$ \\ Received: 30 August 2019 / Accepted: 11 April 2020 / Published online: 8 May 2020 \\ (C) The Author(s) 2020
}

\begin{abstract}
A heat treatment technique was applied on standard duplex stainless steel welds in order to investigate the influence of thermal treatments, e.g., multi-pass welding, on the microstructure. By using a stationary arc, a spatial steady-state temperature field ranging from liquidus to room temperature evolves within a single sample and results in a graded microstructure. The arc heat treatment was applied for 10 and 60 min respectively, and the experimental results were compared against thermodynamic calculations. Metallographic investigations revealed the formation of secondary phases within distinct zones. For the 10 min arc heat treated sample, the formation of sigma phase was observed in a temperature range of $730-1000{ }^{\circ} \mathrm{C}$ and chi phase was found above $700{ }^{\circ} \mathrm{C}$. For the 60 min sample, sigma phase formed between 675 and $1025^{\circ} \mathrm{C}$, while chi phase formed above $600{ }^{\circ} \mathrm{C}$. In both samples, transformation of chi phase to sigma phase as well as the formation of secondary austenite at $575-$ $1100{ }^{\circ} \mathrm{C}$ was observed. Hardness measurements identified brittle regions, which correlated with the regions enriched in sigma phase and decomposition of ferrite. Compared to the initial microstructure, regions with secondary phases showed increased sensitization to local corrosion, when tested according to ASTM A262-Practice A.
\end{abstract}

Keywords Duplex stainless steel $\cdot$ Welding $\cdot$ Physical simulation $\cdot$ Heat treatment

\section{Introduction}

Duplex stainless steels (DSS) combine the advantages of ferritic and austenitic grades. Thanks to their good corrosion resistance, they are used for applications such as desalination plants and chemical and petrochemical industries or for offshore constructions. The main alloying elements are chromium, nickel, molybdenum, and nitrogen. The resistance against stress corrosion cracking is generally as high as for the ferritics, while the ductility and resistance to general corrosion,

Recommended for publication by Commission II - Arc Welding and Filler Metals

Andrea Putz

andrea.putz@andritz.com

1 Institute of Materials Science, Joining and Forming, Graz University of Technolog, $8010 \mathrm{Graz}$, Austria

2 Department of Engineering Science, University Wes, SE-461 86 Trollhattan, Sweden

3 Voestalpine Böhler Welding Austria GmbH, 8605 Kapfenberg, Austria pitting, and crevice corrosion are closer to that of the austenitic alloys. The yield and tensile strengths are significantly higher than for the austenitics, which may allow reducing the wall thickness of constructions when replacing an austenitic stainless steel of similar corrosion resistance. The microstructure of these high-alloyed steels consists of nearly equal amounts of ferrite and austenite. The solidification is fully ferritic and austenite precipitates inter- and intragranular by diffusion controlled solid-state transformations during cooling. Optimum properties are achieved when the ferrite and austenite fraction is close to $50 \%$, and a range of $35-65 \%$ or $30-70 \%$ is often set for welds [1-4]. To guarantee a proper ferrite/austenite ratio for the welds, filler materials have a slightly different chemical composition than the base material. An increase in nickel and nitrogen increases the kinetics of austenite formation during rapid cooling occurring when welding [5]. While standard DSS has a nickel content of approximately 5\%, fillers are over-alloyed and contain about $9 \%$ of nickel. To compensate nitrogen loss when welding, some shielding gases used for these alloys contain nitrogen [6, 7]. However, this nonequilibrium microstructure may change by diffusion controlled phase transformation if certain temperatures are exceeded for a period of time. 
Fig. 1 Schematic illustration of the arc heat treatment equipment

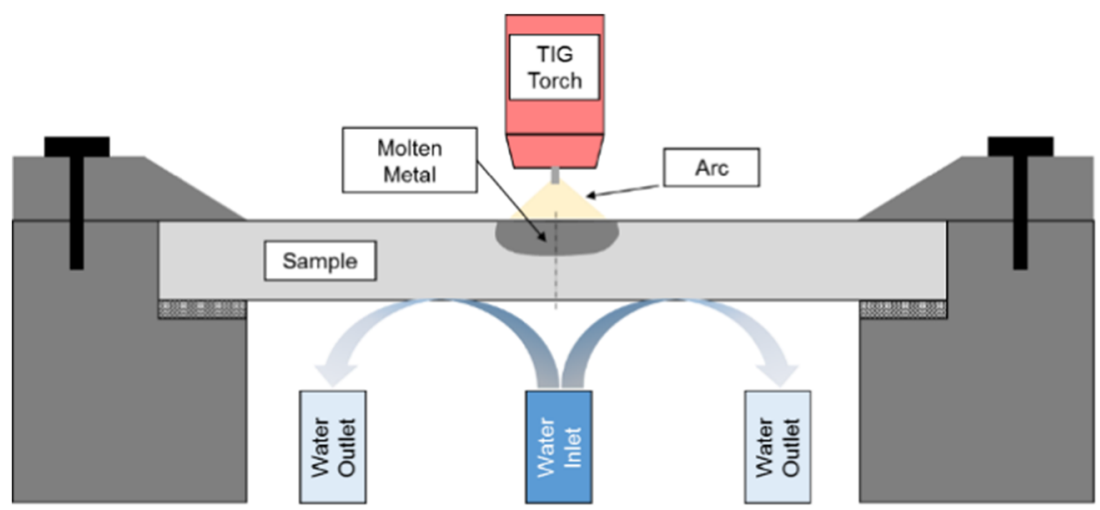

Due to multi-pass welding or inappropriate post-weld heat treatments, the re-heating of previous beads shifts the ferrite/ austenite ratio and can lead to formation of secondary phases such as intermetallics, nitrides, and/or secondary austenite. These phases can be detrimental for the mechanical properties and can cause embrittlement and reduction of the corrosion resistance [4, 8-15]. Common secondary phases observed in DSS are listed below:

- Sigma phase $(\sigma)$ is enriched in chromium and molybdenum and has a tetragonal structure. Formation can occur at 600-1000 ${ }^{\circ} \mathrm{C}$ and lead to decreased ductility, toughness, and corrosion resistance. The preferred nucleation site is at ferrite-austenite grain boundaries, but also at carbides and intermetallics [16, 17].

- Chi phase $(X)$, with a nominal chemical formula of $\mathrm{Fe}_{36} \mathrm{Cr}_{12} \mathrm{Mo}_{10}$, has a body-centered cubic structure and forms at ferrite-austenite grain boundaries at temperatures between $700{ }^{\circ} \mathrm{C}$ and $900{ }^{\circ} \mathrm{C}$ [18]. The influence on corrosion and toughness properties is similar to sigma phase [1].

- Laves or R-phase forms both intergranular and intragranular in the ferritic matrix in DSS at $550-650{ }^{\circ} \mathrm{C}$. This molybdenum-rich phase $\left(\mathrm{Fe}_{2} \mathrm{Mo}\right)$ has a trigonal crystal structure and reduces toughness and the critical pitting temperature [19-21].

- $\mathrm{Cr}_{2} \mathrm{~N}$ and $\mathrm{CrN}$ nitrides precipitate either within the ferrite grains due to supersaturation of nitrogen as the result of rapid cooling or at grain or phase boundaries at 700 $900{ }^{\circ} \mathrm{C}$, e.g., in the heat-affected zone when welding is performed. This precipitation leads to a depletion of chromium in the surrounding matrix, resulting in a decrease in local corrosion resistance [22, 23].

- Secondary austenite $\left(\gamma_{2}\right)$ precipitates when material in metastable condition is reheated, e.g., when multi-pass welding. This additional heat input leads to dissolution of intragranular nitrides in supersaturated ferrite grains and formation of Widmanstätten austenite between 600 and $1100^{\circ} \mathrm{C}$. Secondary austenite contains somewhat less chromium, molybdenum, and nitrogen than the primary austenite. Therefore, secondary austenite is more susceptible to pitting corrosion compared to primary austenite [9, $10,13,24]$.

- So-called $475{ }^{\circ} \mathrm{C}$ embrittlement occurs in a temperature range from 280 to $500{ }^{\circ} \mathrm{C}$ due to decomposition of the ferrite phase into chromium-rich alpha-prime $\left(\alpha^{\prime}\right)$ and iron-rich ferrite. The embrittlement affects the tensile, fracture, and fatigue behavior [25-27].

In order to understand the evolution of precipitates in DSS welds, investigations of the phase transformation are essential. To be able to visualize the results in time-temperaturetransformation diagrams (TTT), a number of samples need to be heat treated at various temperatures and for different durations. The traditional method has been to use a furnace, but as compared to the actual welding process, the heating and cooling rates cannot be reproduced. Physical simulations of the heat-affected zone can instead be carried out in a Gleeble $\AA$ thermo-mechanical simulator. An advantage of this tool is the possibility to vary the thermal cycles and therefore, study the influence of heating and cooling rates, representing different welding conditions [28]. The sample contains a single microstructure and the size can also be sufficiently large for actual impact and corrosion testing. Drawbacks of this method are that the equipment is very expensive, and a large number of samples are needed to create a full TTT diagram. Additionally, the Gleeble can also be used to create a stable temperature gradient in the sample using the proper combination of sample size, $\mathrm{Cu}$ grips, and sufficient cooling. With this approach, the

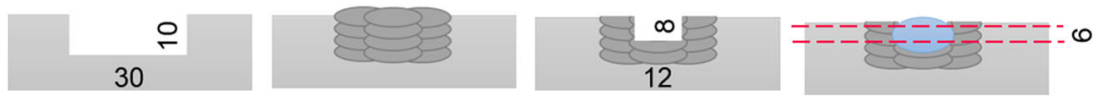

Fig. 2 Manufacturing route: Building up an all-weld metal zone. A disc with $6 \mathrm{~mm}$ thickness (red dashed line) subject to arc heat treated and the final bead is metallographically investigated (bright blue) 
Table 1 Measured chemical composition of DSS flux-core wire allweld metal, wt $\%$

\begin{tabular}{llllllll}
\hline $\mathrm{C}$ & $\mathrm{Si}$ & $\mathrm{Mn}$ & $\mathrm{Cr}$ & $\mathrm{Ni}$ & $\mathrm{Mo}$ & $\mathrm{N}$ & $\mathrm{Fe}$ \\
0.030 & 0.9 & 0.6 & 22.7 & 9.0 & 3.15 & 0.135 & Bal. \\
\hline
\end{tabular}

number of samples for a TTT diagram can be drastically reduced.

Recently, Hosseini et al. [29] developed a heat treatment technique and published their work on super duplex stainless steel $[30,31]$. The main advantage of this method is the simultaneous heat treatment at all temperatures from room temperature to liquidus temperature to achieve a graded microstructure within a single sample. A stationary arc produced by a TIG electrode is ignited in the center of a disc shaped sample's top side and simultaneously water cooled from the bottom side (Fig. 1). Thermocouples were used to measure the actual temperature cycle on the top and bottom side of the discs. According to these measurements, a steady-state temperature field is established within $7 \mathrm{~s}$, due to the symmetrical heat extraction on the disc shaped sample. After the arc is extinguished, the sample cools down rapidly, e.g., from 800 to $200{ }^{\circ} \mathrm{C}$ within $5 \mathrm{~s}$ [29]. Using the results of the thermocouple measurements, a thermal simulation has been modeled, showing the temperature distribution within the sample. By varying the duration of the arc ignition for several samples, different microstructures form and can be connected to their location in the sample and linked to the corresponding calculated temperature. This approach of heat treatment has the advantage that only one sample is needed, per holding time, to cover all temperatures for a TTT diagram. The method can, for instance, be used for fundamental research on formation of intermetallics and for relative fast and inexpensive investigation of new material developments.

The aim of this work was to study the evolution of the microstructure and resulting hardness produced by arc heat treatment of a standard DSS weld metal. Longer heat treatment times ( $10 \mathrm{~min}$ and $60 \mathrm{~min}$ ) were chosen to fill the knowledge gap about the possible influence of multipass welding, wire arc additive manufacturing, and post-weld heat treatment on the microstructure and properties. Microstructural characterization, thermodynamics and kinetics calculations, temperature distribution simulation, as well as hardness and a sensitization test were performed to study the phase transformations occurring from $400{ }^{\circ} \mathrm{C}$ to melting temperature of the DSS weld metal.

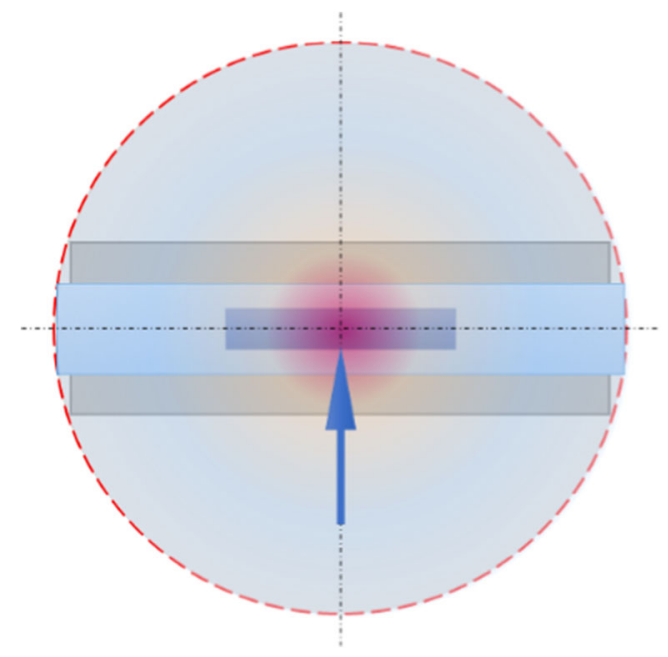

Fig. 3 Top view of plate: discs were cut by waterjet cutting (red dashed line), location of spot weld in center of disc (blurry red), investigated bead (bright blue) with position of samples for metallography with line of sight (dark blue)

\section{Materials and methods}

In order to ensure the examination of all-weld metal in aswelded condition without diluted base material or appearance of secondary austenite, the following manufacturing route was chosen. A groove of $30 \times 10 \mathrm{~mm}$ was milled in a 30 -mm-thick $22 \mathrm{Cr}$ duplex stainless steel (1.4462/UNS S32205) plate. Deposition welding of four layers, each consisting of three beads, was performed using the flux-cored arc welding (FCAW) process in $\mathrm{PA} / 1 \mathrm{~F}$ position. After welding, the surface was machined and another groove with $12 \times 8 \mathrm{~mm}$ was milled in the center. Finally, this groove was filled with the last and investigated bead, performed with the weaving technique to guarantee full penetration and sufficient material deposit (Fig. 2).

The filler metal was a flux-cored wire of T2293NLR/ E2209T0 type with the chemical composition shown in Table 1. The welding parameters were chosen in order to achieve a spray arc transfer (Table 2). The shielding gas composition was argon with $18 \%$ carbon dioxide (M21 Ar C-18).

Two discs were produced by water jet cutting with a diameter of $99 \mathrm{~mm}$ and then turned to a thickness of $6 \mathrm{~mm}$ with a chamfer of $2 \mathrm{~mm} \times 45^{\circ}$ on the bottom side of the disc (Fig. 3).

For the arc heat treatment, the samples were fixed on a water-cooled chamber and the TIG electrode was placed exactly in the center of the sample. Subsequently, the water cooling in the box was turned on and after $1 \mathrm{~min}$, the arc was initiated on the top side of the sample. The constant water

Table 2 Welding parameters

\begin{tabular}{llllll}
\hline $\begin{array}{l}\text { Voltage } \\
(\mathrm{V})\end{array}$ & $\begin{array}{c}\text { Current } \\
(\mathrm{A})\end{array}$ & $\begin{array}{c}\text { Welding speed } \\
(\mathrm{m} / \mathrm{min})\end{array}$ & $\begin{array}{c}\text { Arc energy } \\
(\mathrm{kJ} / \mathrm{mm})\end{array}$ & $\begin{array}{c}\text { Wire feeding } \\
(\mathrm{m} / \mathrm{min})\end{array}$ & Polarity \\
29 & 230 & 0.27 & 1.48 & 14 & $\mathrm{DC}+$ \\
\hline
\end{tabular}


Table 3 Parameters of arc heat treatment

\begin{tabular}{lllll}
\hline Voltage $(\mathrm{V})$ & Current $(\mathrm{A})$ & Arc length $(\mathrm{mm})$ & Water flow $(1 / \mathrm{min})$ & Polarity \\
9.2 & 100 & 3 & 1.4 & DC - \\
\hline
\end{tabular}

flow rate was about $1.4 \mathrm{l} / \mathrm{min}$, the water inlet temperature was about $8^{\circ} \mathrm{C}$, and the outlet temperature was about $18{ }^{\circ} \mathrm{C}$. The current of $100 \mathrm{~A}$ in combination with an arc length of $3 \mathrm{~mm}$ resulted in a voltage of 9.2 $\mathrm{V}$ (Table 3 ). The power source was a Migatronic Commander AC/DC 400 where the TIG welding torch was attached to a welding robot. The electrode used was a common $2 \%$ thorium electrode with a tip angle of $60^{\circ}$ and a diameter of $2.4 \mathrm{~mm}$. The shielding gas was pure argon. The two samples were heat treated for 10 and $60 \mathrm{~min}$.

\subsection{Modeling of temperature distribution and thermodynamic calculations}

The temperature distribution in the bulk of the sample was calculated using the Software COMSOL Multiphysics 5.3. Therefore, the actual sample geometry was used to calculate the temperature gradient from the center of the disc to its edge. Since the heat transfer takes place by heat conduction, the conductive heat transfer within the sample was considered for the simulation of the temperature distribution. Temperatures were measured with thermocouples and defined as boundary conditions. The size of the fusion zone was found using a dummy sample, which was arc heat treated for $30 \mathrm{~s}$ with the same composition and process parameters. The fusion boundary temperature was the calculated melting point of the filler. The temperature dependent parameters such as thermal conductivity, specific heat, and density are from JMatPro, version 6.2.1. JMatPro was also used for calculation of equilibrium phase fractions and TTT diagrams for the actual chemical composition of the filler.

\subsection{Characterization}

Before applying the heat treatment, the ferrite number (FN) was measured at five different positions along the last deposited bead using a calibrated Fischer Feritscope FMP 30. After the heat treatment, samples were cut from the center of the discs using water jet cutting to ensure no additional heat input due to cutting process, which could have influenced the microstructure. This process is crucial because the regions of interest correspond to a temperature and should therefore be carried out with great manufacturing accuracy. Cross sections were prepared for microstructure investigations using standard techniques for metallography. To reveal the microstructure, two different etchants were applied on the polished cross sections: $10 \mathrm{wt} \% \mathrm{NaOH}(4 \mathrm{~V})$ to reveal intermetallic phases [32] and a modified Beraha II solution for ferrite fraction measurement which was performed by image analysis using a magnification of $\times 500[33,34]$. Sensitization testing was performed based on ASTM A 262-Practice A using 10\% oxalic acid and $2 \mathrm{~V}$ for $60 \mathrm{~s}$ to detect the resistance to intergranular corrosion [35]. The light optical microscope used was a Zeiss Axio Imager 2; the scanning electron microscope (SEM) was a Hitachi TM3000 used in back scattered electron mode. This model allowed characterization of secondary phases based on their atomic weight. Vickers hardness measurements HV0.2 were performed according to EN ISO 6507 1:2016 using an Emco M1C, [36]. For this purpose, $95 \times 46$ hardness impressions were applied with a dwell time of $10 \mathrm{~s}$ at a distance of $0.12 \mathrm{~mm}$ each.

\section{Results}

\subsection{Temperature distribution simulation}

Using results of thermocouple measurements, the temperature distribution in the cross of the arc heat treated sample was calculated (Fig. 4). The temperature is uniformly distributed along the fusion boundary. The temperature on the top of the disc as a function of the distance to the fusion line is seen in Fig. 5. Here the temperature drops to $400{ }^{\circ} \mathrm{C}$ in $5.5 \mathrm{~mm}$ from the fusion line. After a heating time of around $7 \mathrm{~s}$, the
Fig. 4 Simulated temperature distribution in the cross section of a disc during arc heat treatment

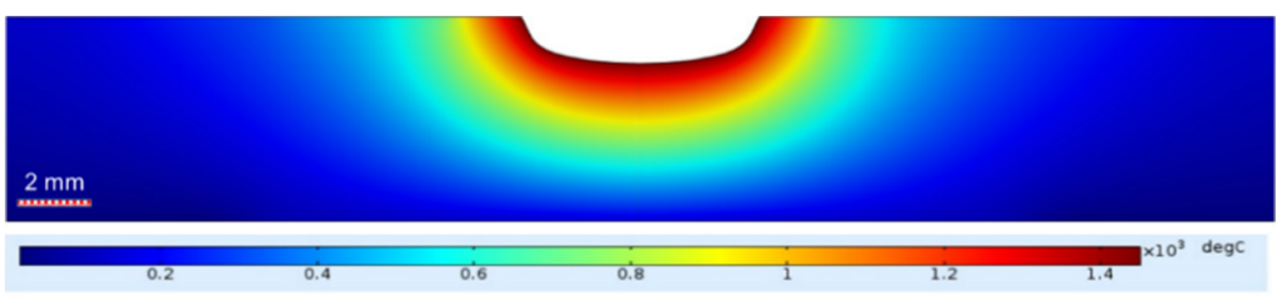


Fig. 5 Simulated temperature on top surface of a disc during arc heat treatment

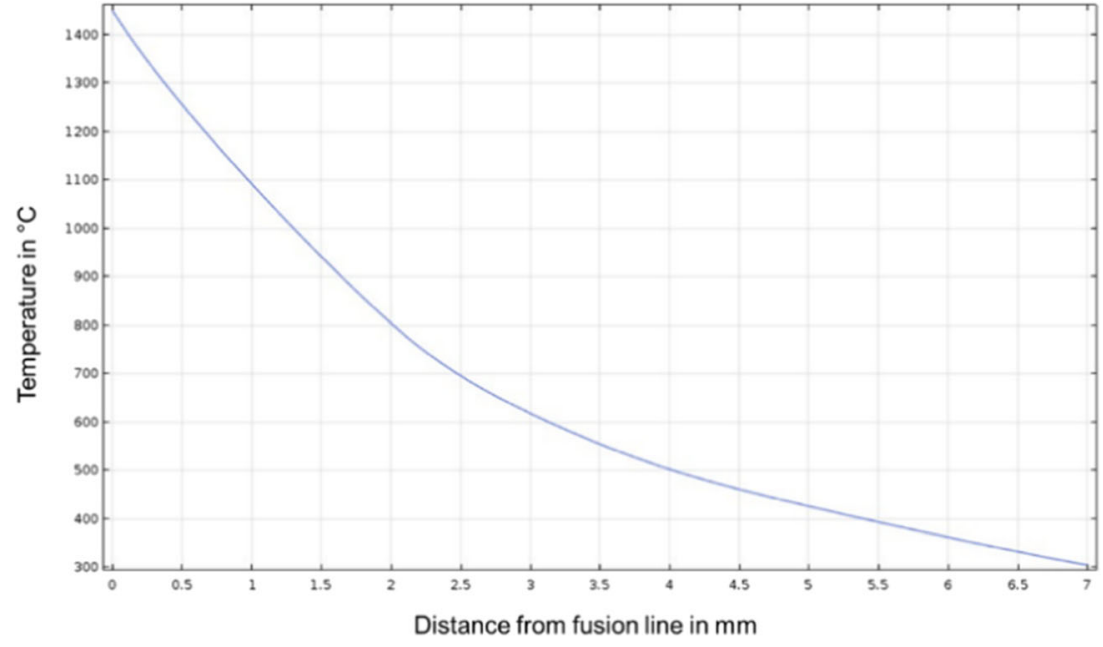

temperature in each location was constant during the experiment. This temperature profile is valid for both samples.

\subsection{Thermodynamic calculations and kinetics of phase transformations}

The equilibrium phase fraction diagram calculated for the chemical composition of filler metal is seen in Fig. 6a. At
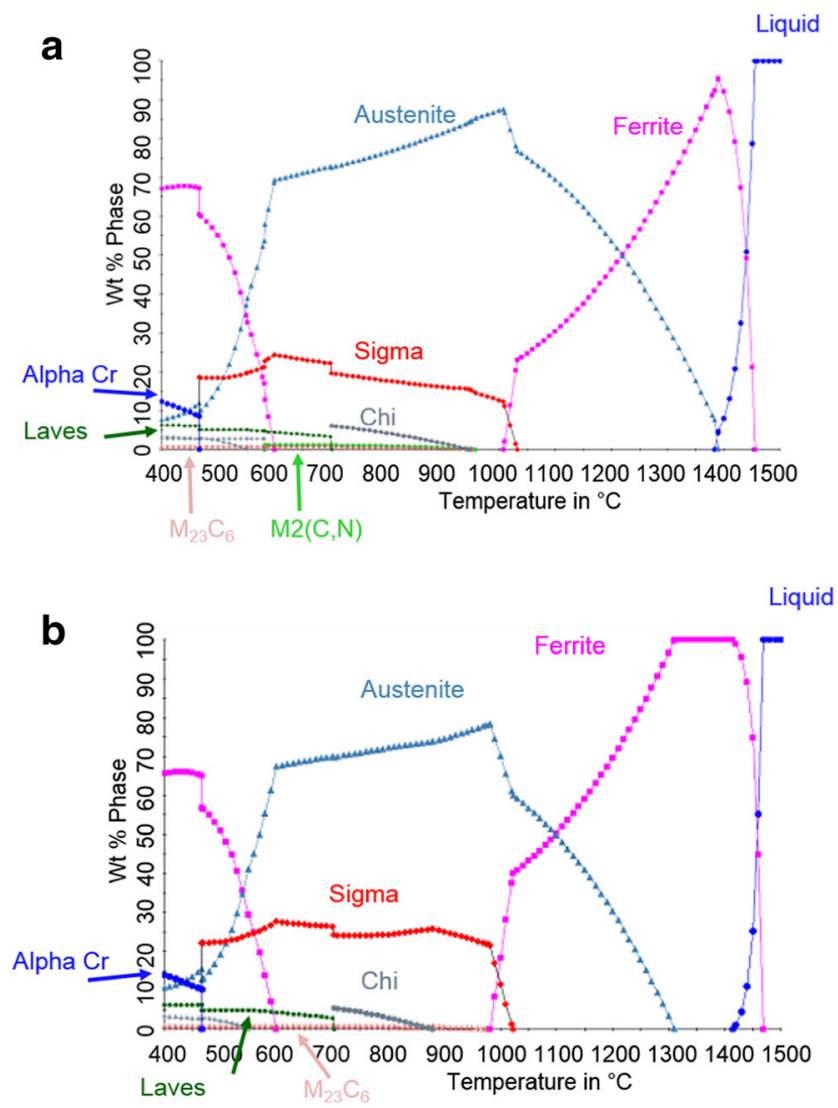

Fig. 6 Equilibrium phase fraction diagram. a The actual composition. b The composition without nitrogen; starting austenite formation temperature is lower for the composition without nitrogen the end of the ferritic solidification, some austenite already forms at $1390{ }^{\circ} \mathrm{C}$. Different secondary phases such as sigma phase, chi phase and laves phase are predicted to form at a temperature range of $400-1040{ }^{\circ} \mathrm{C}$. The temperature where the ferrite and austenite fraction is equaled, 50/50, is at $1200{ }^{\circ} \mathrm{C}$. Sigma phase forms at $1040{ }^{\circ} \mathrm{C}$ and can reach a maximum of $25 \%$. Chi phase forms at lower temperature around $950{ }^{\circ} \mathrm{C}$ down to $700{ }^{\circ} \mathrm{C}$, with a maximum obtainable fraction of $5 \%$. The alpha-prime formation is predicted to occur at $475{ }^{\circ} \mathrm{C}$. As the arc heat treatment is carried out for several minutes using pure argon, the equilibrium phase fraction diagram for a modified chemical composition of the filler metal is necessary; Fig. $6 \mathrm{~b}$ shows the diagram for the same filler metal, but without any nitrogen and shows that nitrogen loss decreases the austenite formation temperature to $1300^{\circ} \mathrm{C}$.

The calculated TTT diagram for the filler metal is shown in Fig. 7. It predicts the formation of sigma phase in a temperature range from 730 to $1020^{\circ} \mathrm{C}$ after $10 \mathrm{~min}$ and approximately from 670 to $1030^{\circ} \mathrm{C}$ after $60 \mathrm{~min}$ (Fig. 7). The nose of

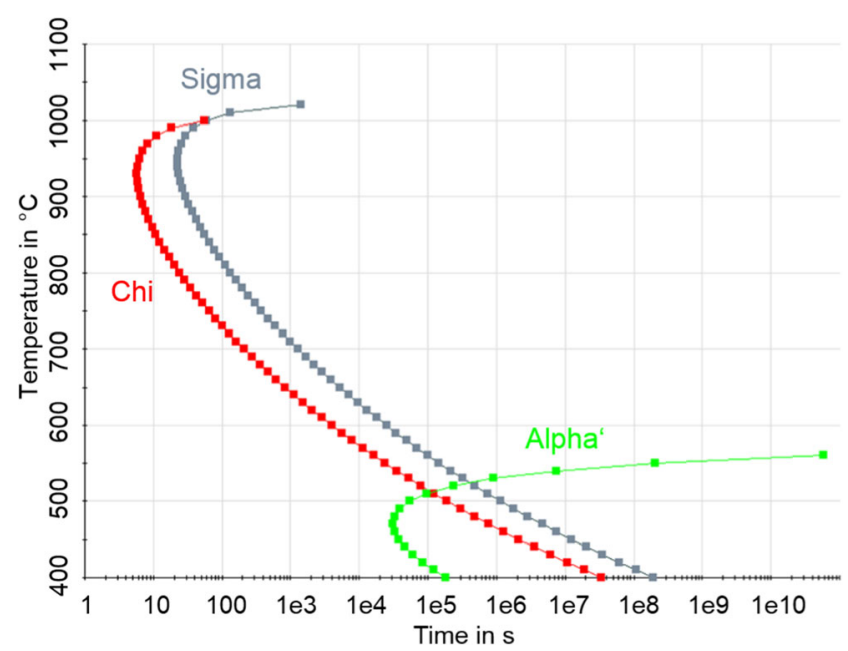

Fig. 7 Calculated TTT diagram for the filler metal chemical composition used in this work showing the formation of sigma phase, chi phase, and $\alpha$ '-phase 


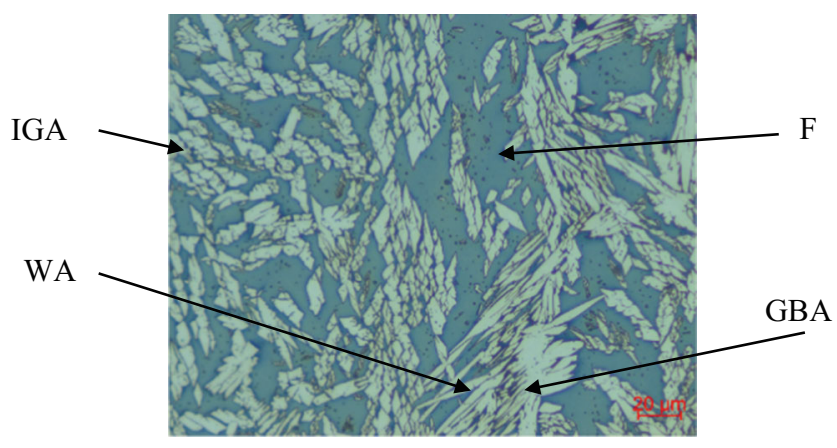

Fig. 8 Microstructure of the all-weld metal in as-welded condition including grain boundary (GBA), Widmanstätten (WA) and intragranular austenite (IGA) in ferritic matrix (F), and ferrite fraction 53\% according to image analysis

sigma phase is located at $950{ }^{\circ} \mathrm{C}$ after $30 \mathrm{~s}$. Chi phase forms above $650{ }^{\circ} \mathrm{C}$ after $10 \mathrm{~min}$ and from 600 to $950{ }^{\circ} \mathrm{C}$ after $60 \mathrm{~min}$. The nose of the $475{ }^{\circ} \mathrm{C}$ embrittlement (50\% drop of impact toughness) is at $30000 \mathrm{~s}$ (500 $\mathrm{min})$ in this alloy composition.

\subsection{Microstructure}

The ferrite number of the investigated beads was $51 \pm 4 \mathrm{FN}$ according to the Feritscope measurements, which is approximately $45 \%$ ferrite and $55 \%$ austenite [37]. In contrast, the image analysis of five images revealed an average ferrite fraction of $55 \%$ and $45 \%$ of austenite (Fig. 8). Deviations of 10 $20 \%$ between Feritscope and image analysis are frequently reported $[34,38,39]$ and are probably a result of the strongly textured microstructure of DSS welds. Non-heat treated allweld metal showed the typical structure of a ferritic matrix and austenite islands. No intermetallics, nitrides, and/or secondary austenite were observed (Fig. 8).

Images of the cross sections after heat treatment are seen in Fig. 9 a and b. Related to the temperature distribution, a difference in the etching response can be seen clearly for the two samples. The areas with the same etch appearance in the arc heat treated samples are expected to have the same type of microstructure and local chemical composition. These areas are slightly bigger for the $60 \mathrm{~min}$ sample compared to the 10 min sample.

The fusion boundary according to the dummy-sample is shown using a dashed line in Fig. 9. Both the fusion zone (FZ) and the adjacent high-temperature heat-affected zone (HTHAZ) are fully ferritic in both samples. This fully ferritic area is bigger for the $60 \mathrm{~min}$ sample compared to the $10 \mathrm{~min}$ sample. Next to the fully ferritic area, austenite starts to form at $1330{ }^{\circ} \mathrm{C}$ in the $10 \mathrm{~min}$ sample and at $1290^{\circ} \mathrm{C}$ in the $60 \mathrm{~min}$ sample. The microstructure at the $1200{ }^{\circ} \mathrm{C}$ isotherm consists of equal amounts of ferrite (blue colored) and austenite (white) according to image analysis (Fig. 10a).

Figure $10 \mathrm{~b}$ shows the microstructure $2 \mathrm{~mm}$ away from the fusion line where the temperature is around $800{ }^{\circ} \mathrm{C}$. According to image analysis, the amount of bright pixels which are primary austenite is $55 \%$. The ferritic matrix transformed to secondary austenite and sigma phase. Secondary austenite was observed above $700{ }^{\circ} \mathrm{C}$ in the sample heat treated for $10 \mathrm{~min}$ and above $575{ }^{\circ} \mathrm{C}$ in the sample heat treated for $60 \mathrm{~min}$ (Fig. 11). Examples of typical secondary austenite morphology are seen in Fig. 11e-g. At lower temperatures than what is reported in Fig. 11, there was no noticeable effect on the ferrite-austenite ratio according to image analysis.

For phase characterization, the electron back-scatter mode was used, which means that the higher the atomic mass of the phase, the brighter it is displayed in the SEM images. Sigma phase formation was observed in a temperature range of $740-1000{ }^{\circ} \mathrm{C}$ for the $10 \mathrm{~min}$ sample and 675 $1025{ }^{\circ} \mathrm{C}$ for the $60 \mathrm{~min}$ sample (Fig. 11). The formation occurred at ferrite-austenite grain boundaries. For all temperatures, the fraction of sigma phase was much higher in the sample heat treated for $60 \mathrm{~min}$. According to image analysis, the maximum fraction of sigma phase was about $25 \%$ in both samples in a temperature range of $730-930^{\circ} \mathrm{C}$.
Fig. 9 Cross sections etched by $\mathrm{NaOH}$ and temperature distribution (in $\times 10^{3}{ }^{\circ} \mathrm{C}$ ) for samples welded for a $10 \mathrm{~min}$ and b $60 \mathrm{~min}$; the red dashed line shows the fusion line according to the dummy sample

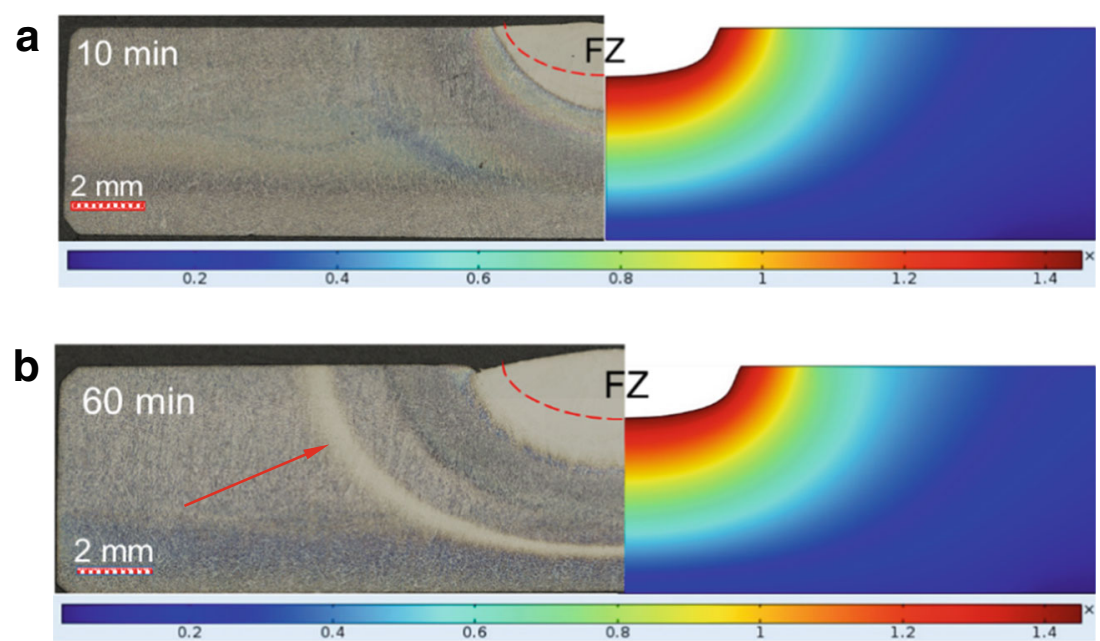


Fig. 10 Microstructure of $10 \mathrm{~min}$ sample: a $1200{ }^{\circ} \mathrm{C}: 50 \%$ ferrite (blue) and 50\% austenite (bright); b $800{ }^{\circ} \mathrm{C}$ : formation of secondary austenite and sigma phase in ferritic matrix
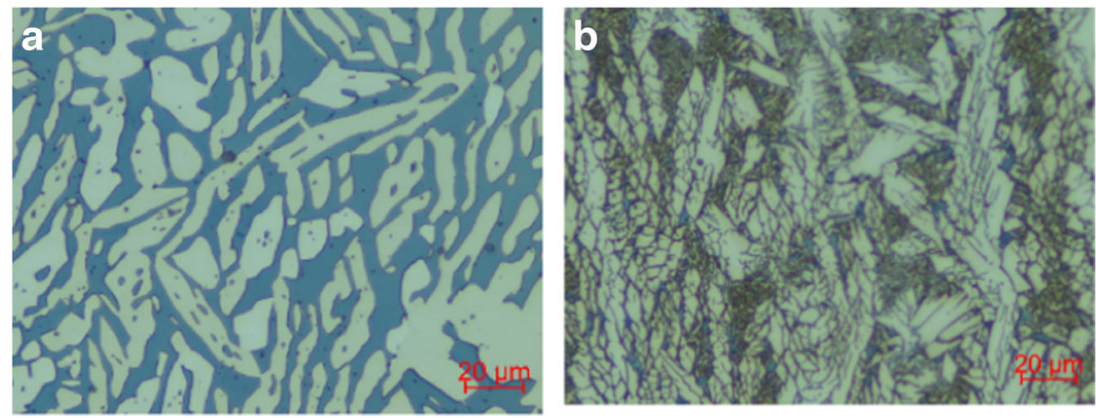

Sigma phase is coarser at high temperature, while it became less coarse at lower temperature. One interesting observation is the growth of sigma phase between secondary austenite clusters. As shown in Fig. 11 e and f, clusters of the secondary austenite formed during heat treatment, while sigma phase was only present between primary austenite. In the sample heat treated for $60 \mathrm{~min}$, however, sigma phase was also observed between secondary austenite clusters (Fig. 11f).

Chi phase was found above $700{ }^{\circ} \mathrm{C}$ for the 10 min sample and above $600{ }^{\circ} \mathrm{C}$ for the $60 \mathrm{~min}$ sample (Fig. 11). Chi phase formed on ferrite-austenite grain boundaries as fine particles. In the sample heat treated for $10 \mathrm{~min}$, the maximum fraction of chi phase was seen at $770-890^{\circ} \mathrm{C}$. For $60 \mathrm{~min}$, in contrast, the maximum fraction was at $655-675{ }^{\circ} \mathrm{C}$. As indicated in Fig. $11 \mathrm{~g}$ at $675^{\circ} \mathrm{C}$ after $60 \mathrm{~min}$ by "R?", there is some indication of intragranular bright precipitates, which are not expected to be chi phase. As they are bright, they are enriched by molybdenum.

Some traces of nitrides/carbides (black precipitates) were also seen in both samples. However, due to the presence of a lot of inclusions, it was not possible to confirm whether they are nitrides/carbides or not.

The ferrite austenite fraction remained constant at lower temperature. The other interesting observation in the cross sections was the different etching response at the $475^{\circ} \mathrm{C}$ isotherm, as indicated by the arrow in Fig. 9b. The response is more obvious and covers a larger area in the sample heat treated for $60 \mathrm{~min}$.

\subsection{Hardness}

Before the heat treatment, the material had hardness values around 300 HV0.2. The hardness map after heat treatment for both samples is seen in Fig. 12. The fusion zone shows slightly higher values than the initial material. The HTHAZ where solid-state nitrogen depletion occurred has the lowest hardness values. Next to this fully ferritic area the highest values, e.g., up to $471 \mathrm{HV} 0.2$ for the $60 \mathrm{~min}$ sample, were measured. In the region, which showed almost no etching effect and remained white, another slight increase in hardness is observed Fig. 16.

\subsection{Sensitization}

When etched with $10 \%$ oxalic, both samples showed significant response acid in the area linked to the temperature range between 600 and $1020{ }^{\circ} \mathrm{C}$, being strongest between 700 and $900{ }^{\circ} \mathrm{C}$ (Fig. 13). The etching response increased with increasing duration of the heat treatment. The response was stronger in the matrix compared to the islands because of stronger dissolution of the ferrite matrix resulting in a "rough" surface that reflects less light and gets visually darker.

\section{Discussion}

The phase equilibrium diagram shows that the austenite formation should start before finishing the solidification. However, the as-solidified weld metal shows the fully ferritic solidification followed by solid-state austenite formation. Since the cooling rate during welding is very high, an equilibrium state as predicted by the calculated diagram is not reached.

After arc heat treatment, the fully ferritic region, present in the weld spot and along the fusion boundary in the HTHAZ, was expected as it had previously been observed and reported by Hosseini et al. [30, 31]. The use of pure argon as shielding gas for 10 and $60 \mathrm{~min}$ depletes this area from nitrogen. The equilibrium phase fraction for the same chemical composition, but without nitrogen was calculated and shown in Fig. 6b. The absence of nitrogen caused a reduction of the austenite formation temperature from $1390{ }^{\circ} \mathrm{C}$ with nitrogen to about $1300{ }^{\circ} \mathrm{C}$. This simulation is in good agreement with the austenite formation temperature of $1290{ }^{\circ} \mathrm{C}$ observed in the sample heat treated for $60 \mathrm{~min}$. The actual nitrogen loss in the high temperature heat-affected zone during welding will be much smaller, or even negligible, since the necessary temperatures are not reached for these long times and the driving force is smaller with nitrogen still present in the weld metal. Filler metals are alloyed with nitrogen as nitrogen loss from the weld metal can lead to reduced pitting corrosion resistance and an unbalanced microstructure with more ferrite and therefore a negative effect on the ductility [40]. 
Fig. 11 SEM images for $10 \mathrm{~min}$ sample (left) and $60 \mathrm{~min}$ sample (right) at different temperatures showing sigma phase $\sigma$, chi phase $\chi$, secondary austenite $\gamma_{2}$ and some not identified precipitations "R?"

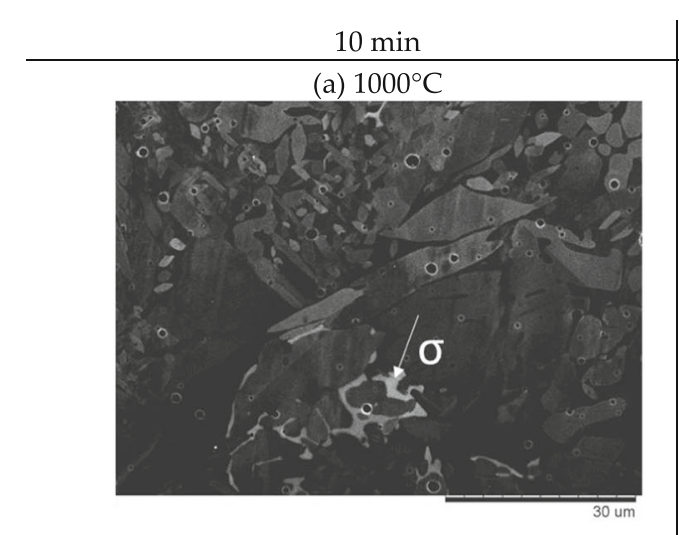

(c) $890^{\circ} \mathrm{C}$

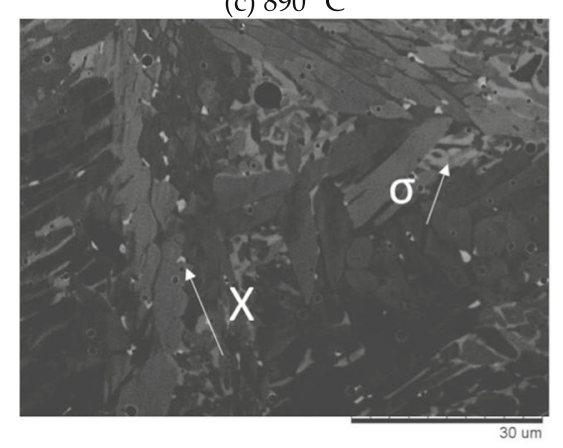

(e) $770{ }^{\circ} \mathrm{C}$

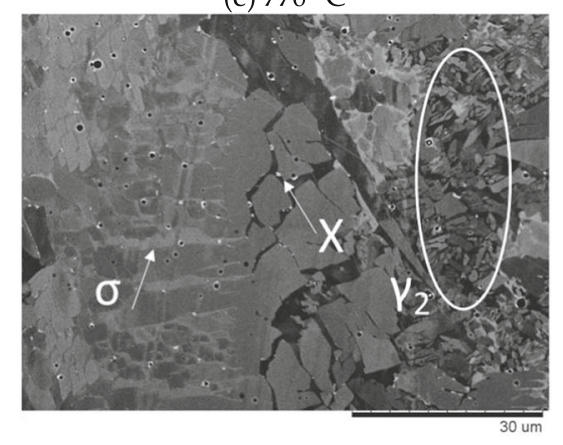

$60 \mathrm{~min}$

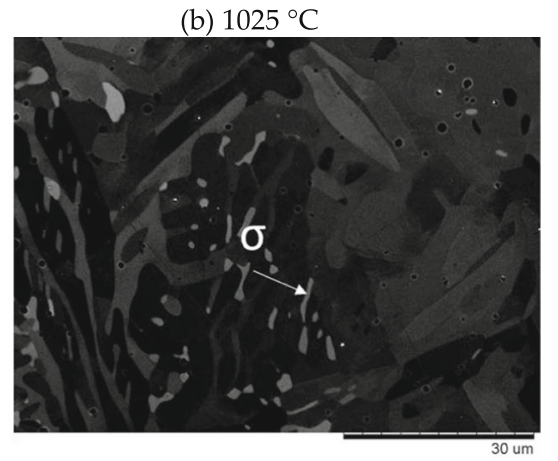

(d) $870^{\circ} \mathrm{C}$

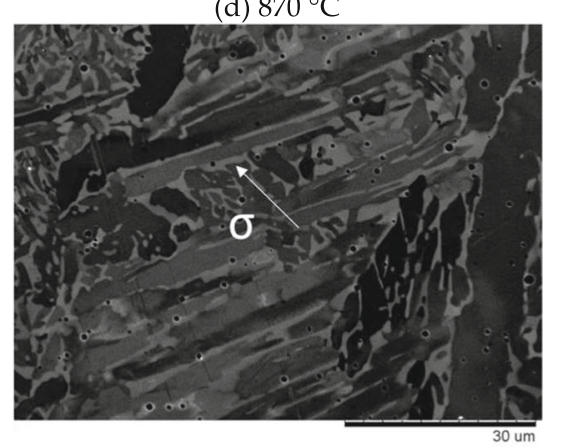

(f) $770{ }^{\circ} \mathrm{C}$

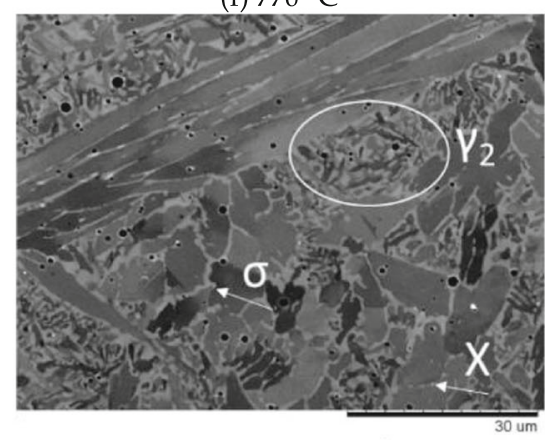

(g) $675^{\circ} \mathrm{C}$

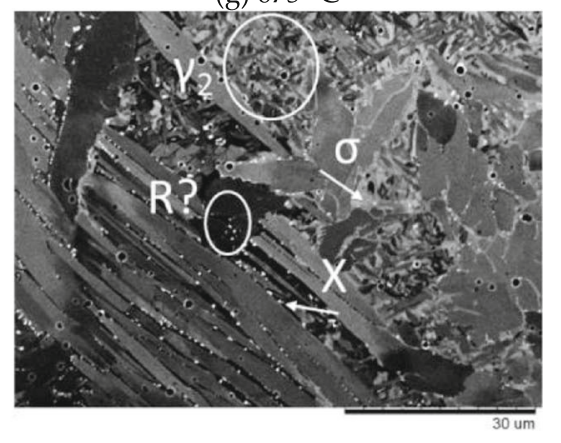

The ferrite/austenite fraction of $50 / 50$ at $1200{ }^{\circ} \mathrm{C}$ is in very good agreement with the thermodynamic calculations in the equilibrium phase diagram of the filler metal. It verifies that the thermodynamic calculation properly predicts austenite fraction produced during arc heat treatment.
When etched with Beraha II, the ferrite shows etching colors from yellow/brown to blue, depending on the individual chemical composition (Fig. 14). Since the etching contrast in some areas is too low, the ferrite fraction cannot be measured by image analysis, for example for the $60 \mathrm{~min}$ sample at $1000{ }^{\circ} \mathrm{C}$ (Fig. 15). 

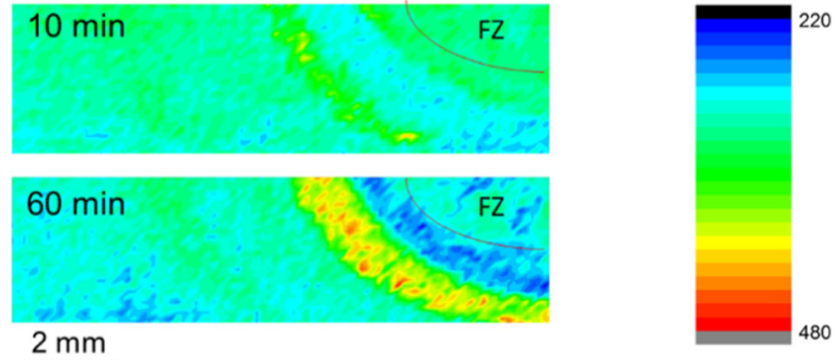

Fig. 12 Hardness map for $10 \mathrm{~min}$ and 60 min sample with illustrated fusion zone

The most critical temperature range from the view of detrimental phase transformation was $400-1040{ }^{\circ} \mathrm{C}$. The microstructure contains substantial amounts of secondary phases such as secondary austenite, sigma phase, and chi phase, as well as $475^{\circ} \mathrm{C}$ embrittlement.

Sigma phase was observed down to $675{ }^{\circ} \mathrm{C}$ which is in good agreement with the calculated TTT diagrams in Fig. 7a. Also the measured maximum fraction of $25 \%$ for the 60 min sample is in good agreement with the prediction of the equilibrium phase fraction diagram in Fig. 6a.

Chi phase precipitated in a very small amount at the ferriteaustenite grain boundaries. The thermodynamic calculations predicted chi phase formation at $700-900{ }^{\circ} \mathrm{C}$, while the experiment showed that chi phase is not a stable phase. Interestingly it formed outside of its stability range predicted by equilibrium phase diagram in the $60 \mathrm{~min}$ heat treated sample $\left(675^{\circ} \mathrm{C}\right)$. The phase was not observed above $730^{\circ} \mathrm{C}$ in the $60 \mathrm{~min}$ heat treated sample and got replaced by sigma phase. The influence on the mechanical behavior of chi phase might be marginal, but it can serve as a nucleation site for sigma phase [16].

In addition to sigma and chi phase, some not identified secondary phases were observed in the region above $575{ }^{\circ} \mathrm{C}$ in the sample heat treated for $60 \mathrm{~min}$. Karlsson et al. [14] reported R-phase formation at almost the same temperature in standard DSS weld metal. This suggests that the observed phase here may be R-phase as well, but further characterization is needed to be certain.
A comparison of the hardness map for both samples is seen in Fig. 12. Longer heat treatment time leads to higher hardness values, which are measured in the area where secondary phases formed. Especially at the location or temperature at which most sigma phase was found, the highest hardness values were measured. The negative effect of sigma phase on the mechanical properties and especially ductility is well known [14, 41, 42]. Therefore, controlled heat input and interpass temperature are essential for good welding practice. The second hardness increase was observed where the contrast after etching was very low for the $60 \mathrm{~min}$ sample (Fig. 16). At this position, the classical temperature for $475{ }^{\circ} \mathrm{C}$ embrittlement was reached during the heat treatment. Hosseini et al. [30] observed increased hardness values in the same region for super duplex stainless steel. The embrittlement is caused by spinodal decomposition to iron-rich ferrite $(\alpha)$ and chromium-rich $\alpha^{\prime}$ phase [27]. Although the calculated TTT diagram predicted the decomposition only after 600 min (Fig. 7), the calculated equilibrium phase diagram in Fig. 6 was able to predict the decomposition of the alloy at $475{ }^{\circ} \mathrm{C}$.

Using $10 \%$ oxalic acid to test the sensitivity for local corrosion in DSS welds showed the strongest etching response in areas where most precipitations and secondary phases formed. Secondary austenite, in contrast to primary austenite, has a lower content of the alloying elements chromium, molybdenum and nitrogen [13]. However, these elements are essential for high pitting resistance, as shown by the pitting resistance equivalent number PREN $=\% \mathrm{Cr}+3.3 \% \mathrm{Mo}+16 \% \mathrm{~N}$. If phases have a lower PREN, they are more susceptible to pitting corrosion [43]. In addition, sigma phase is also disadvantageous for the corrosion resistance since the phase forms at the ferrite-austenite grain boundaries in solid state and leads to a depletion of alloying elements in its immediate environment which in turn becomes more susceptible to pitting corrosion [1]. If the recommendations for welding of standard DSS are followed, however, there should be no formation of sigma phase.

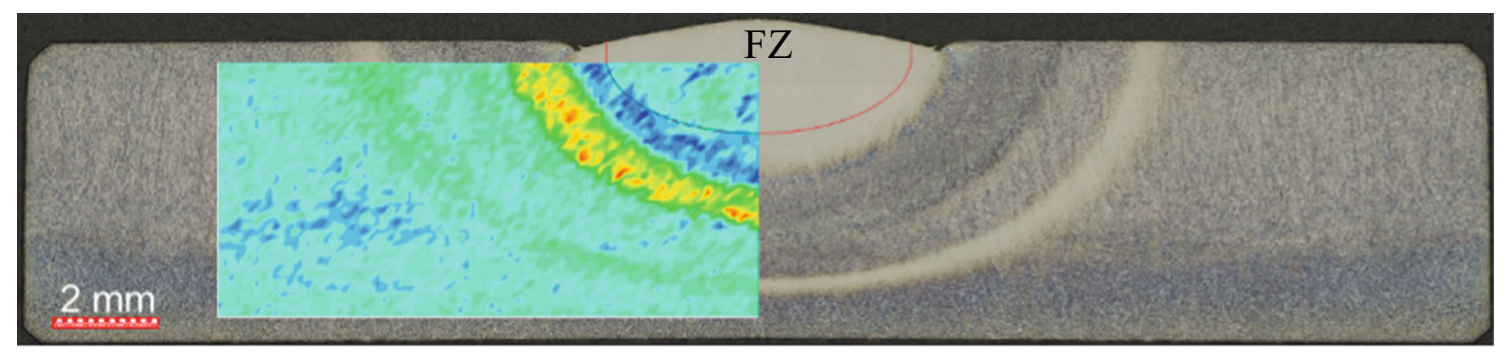

Fig. 16 Microhardness map of 60 min sample on cross section with fusion zone (FZ) 
Fig. 13 Results of sensitization test, showing local corrosion attacks, samples etched with $10 \%$ oxalic acid, intragranular area etched strongly, austenite remains white; 10 min sample (left) and 60 min sample (right) at 900,800 , and $700{ }^{\circ} \mathrm{C}$

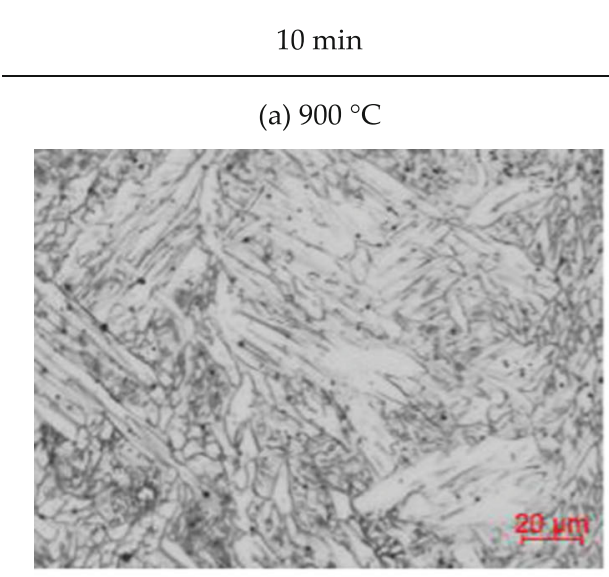

(c) $800{ }^{\circ} \mathrm{C}$

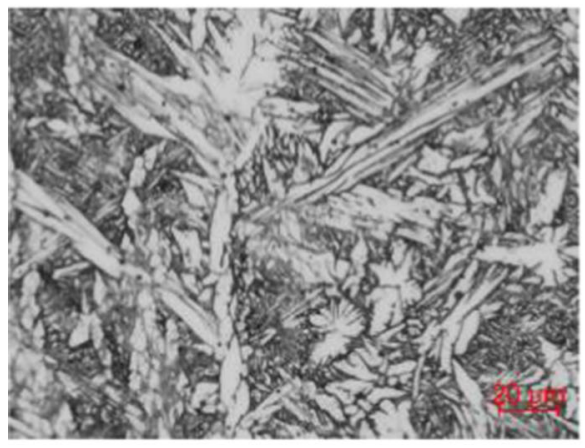

(e) $700{ }^{\circ} \mathrm{C}$

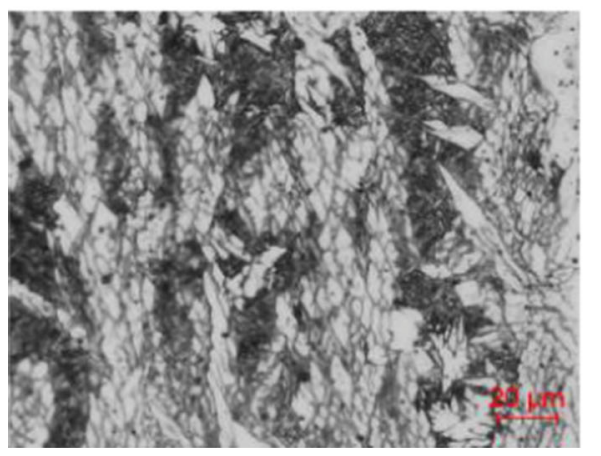

$60 \mathrm{~min}$

(b) $900{ }^{\circ} \mathrm{C}$

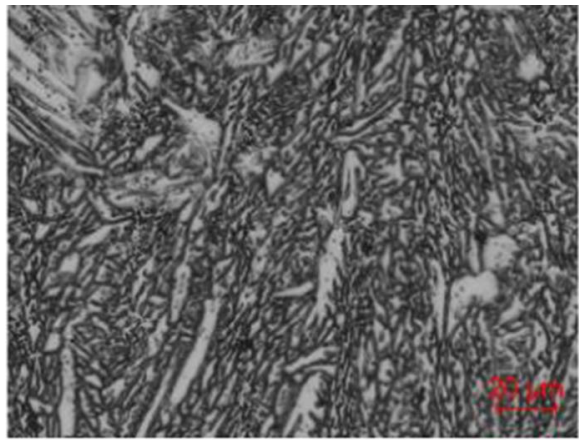

(d) $800{ }^{\circ} \mathrm{C}$

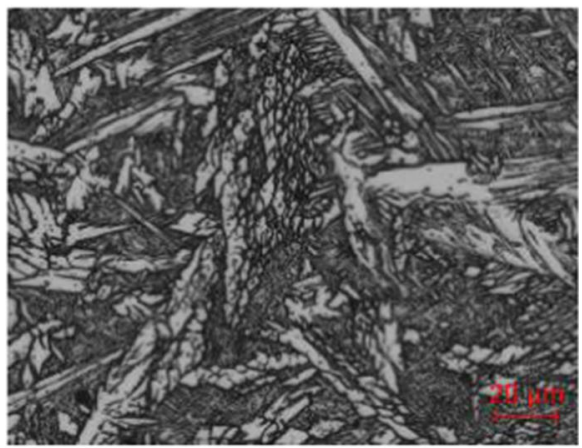

(f) $700{ }^{\circ} \mathrm{C}$

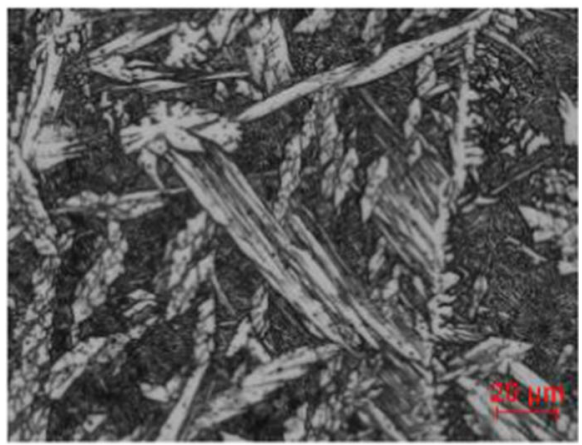

\section{Summary and conclusions}

Phase transformations in a standard DSS weld metal was studied using an arc heat treatment technique. A stationary arc was applied for 10 and $60 \mathrm{~min}$ on an all-weld metal disc with water-cooling from the backside, thus leading to a steadystate temperature field from room to melting temperature in one sample. The developed microstructure and hardness were investigated and compared to results of thermodynamic calculations.

- Due to the use of pure argon as shielding gas, nitrogen was completely depleted in the fusion zone and the adjacent high-temperature heat-affected zone. This reduced the start temperature for austenite formation from 1390 to $1330{ }^{\circ} \mathrm{C}$ for the sample heat treated for 10 min sample and to $1290{ }^{\circ} \mathrm{C}$ for the sample heat treated for $60 \mathrm{~min}$.

- Sigma phase formation was observed in a temperature range of $730-1000{ }^{\circ} \mathrm{C}$ for the 10 min sample and 675 $1025^{\circ} \mathrm{C}$ for the $60 \mathrm{~min}$ sample.

- Chi phase was found above $700{ }^{\circ} \mathrm{C}$ for the $10 \mathrm{~min}$ sample and $600{ }^{\circ} \mathrm{C}$ for the 60 min sample. Chi phase was transformed to sigma phase at longer heat treatment time.

- Formation of secondary austenite was observed at 575$1100{ }^{\circ} \mathrm{C}$ in both samples. 
Fig. 14 Cross sections of $10 \mathrm{~min}$ (left) and $60 \mathrm{~min}$ (right) samples etched with a $\mathrm{NaOH}, \mathbf{b}$ Beraha II, and $\mathbf{c}$ oxalic acid a
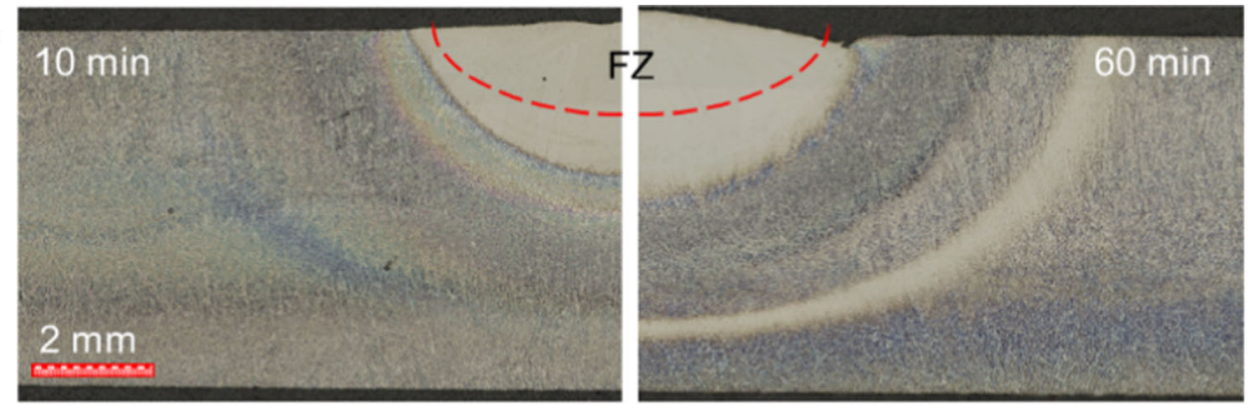

b
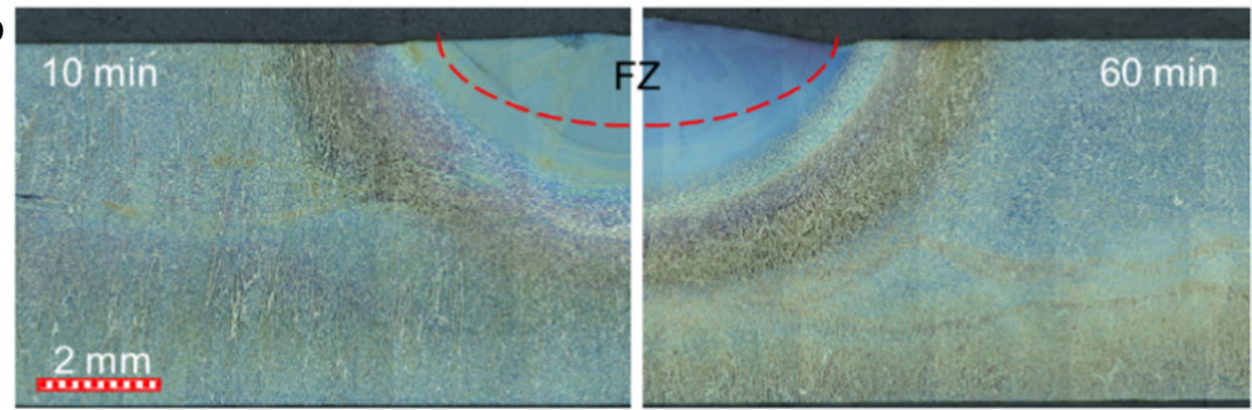

c

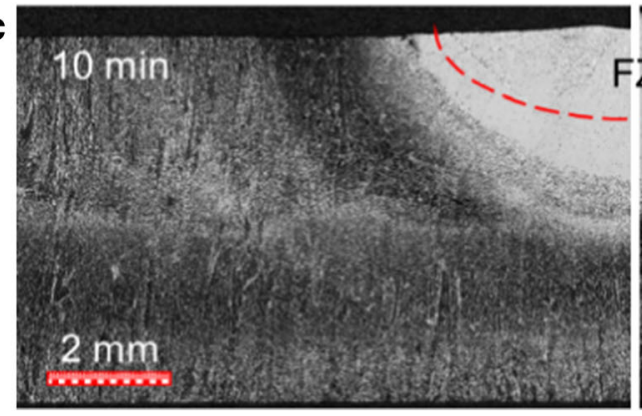

- Decomposition of ferrite was predicted in the equilibrium phase fraction diagrams, and $\alpha^{\prime}$ was observed in the region that reached $475^{\circ} \mathrm{C}$.

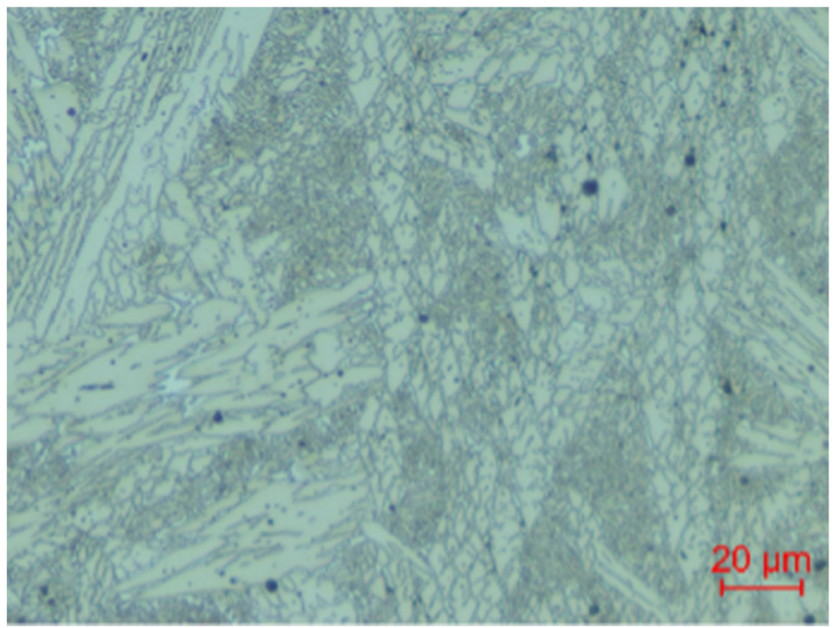

Fig. 15 Sixty-minute sample at $1000{ }^{\circ} \mathrm{C}$, most ferrite transfer to sigma phase and secondary austenite
- Secondary phases increased the sensitization to intergranular corrosion as compared to the initial ferritic-austenitic microstructure.

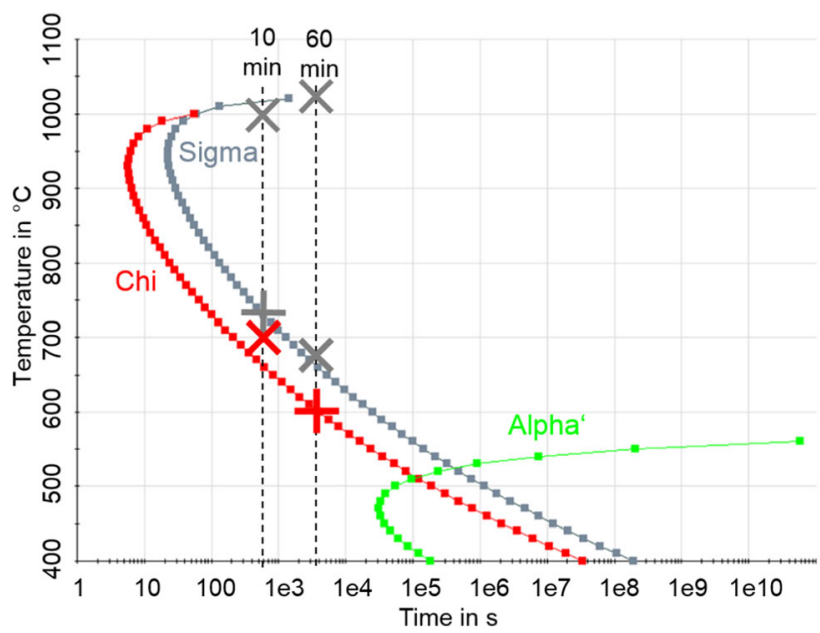

Fig. 17 Calculated TTT diagram compared with results from arc heat treatment for both samples: temperature of first and last formation marked by crosses at 10 and $60 \mathrm{~min}$ 
- Hardness measurements showed regions with embrittlement. The sigma phase formation coincided with the area showing the highest hardness increase and also the region suspected to suffer from $475^{\circ} \mathrm{C}$ embrittlement was shown as increased hardness.

- Thermodynamic calculations predicted austenite ferrite fraction correctly at temperature above $1100{ }^{\circ} \mathrm{C}$. Equilibrium and TTP diagrams showed good agreement with the experiential results for the sigma phase formation (Fig. 17). The chi phase, however, was not an equilibrium phase, while JMatPro suggested that it is a stable phase.

The present study showed that arc heat treatment can be used to study the complex microstructure evolution in duplex stainless steel welds with a minimum of experiments. Combined with numerical simulation and proper etching techniques, useful information about phase transformation during welding can be revealed. To measure the austenite/ferrite fraction, the most suitable method is image analysis on properly prepared surfaces etched with a Beraha II etchant. To study the secondary phases, particularly sigma phase and $475^{\circ} \mathrm{C}$ embrittlement, etching in $\mathrm{NaOH}$ is to be preferred. A sensitization test using oxalic acid can provide useful information about the area most prone to intergranular corrosion. The selection of etching method can be an important key to characterize the DSS weld metal microstructure.

The results from arc heat treatment can be translated to post-weld heat treatments of multi-pass welded or additive manufactured structures. The repeated heating or improper heat treatment at temperatures between 400 and $1030{ }^{\circ} \mathrm{C}$ can cause unwanted phase transformations in DSS. This situation is more critical for temperatures between 700 and $1000{ }^{\circ} \mathrm{C}$. Compared to base material, DSS all weld metal is more prone to formation of intermetallic phases. Compared to super duplex stainless steels weld metal, the kinetic of transformation is much slower.

Acknowledgments Open access funding provided by Graz University of Technology. The authors like to thank Kjell Hurtig for performing the experiments, Chamara Kumara for his support on the simulation and Florian Pixner for the hardness measurements.

Author contributions Investigation, Andrea Putz; Software, Vahid A. Hosseini; Supervision, Norbert Enzinger; Writing — original draft, Andrea Putz; Writing - review and editing, Vahid A. Hosseini and Elin M. Westin.

Funding information This research was funded by Österreichische Forschungsförderungsgesellschaft.

\section{Compliance with ethical standards}

Conflict of interest The authors declare that they have no conflict of interest.
Disclaimer The funders had no role in the design of the study; in the collection, analyses, or interpretation of data; in the writing of the manuscript; or in the decision to publish the results.

Open Access This article is licensed under a Creative Commons Attribution 4.0 International License, which permits use, sharing, adaptation, distribution and reproduction in any medium or format, as long as you give appropriate credit to the original author(s) and the source, provide a link to the Creative Commons licence, and indicate if changes were made. The images or other third party material in this article are included in the article's Creative Commons licence, unless indicated otherwise in a credit line to the material. If material is not included in the article's Creative Commons licence and your intended use is not permitted by statutory regulation or exceeds the permitted use, you will need to obtain permission directly from the copyright holder. To view a copy of this licence, visit http://creativecommons.org/licenses/by/4.0/.

\section{References}

1. Gunn RN (1997) Duplex stainless steels: microstructure, properties and applications. Woodhead Publishing Ltd., Cambridge ISBN 9781855733183

2. Karlsson L (2000) Welding of stainless steels. Duplex and superduplex steels. Weld Int 14:5-11

3. Berglund G, Wilhelmsson P (1989) Fabrication and practical experience of duplex stainless steels. Mater Des 10:23-28

4. Knyazeva M, Pohl M (2013) Duplex steels: part I: genesis, formation, structure. Metallogr Microstruct Anal 2:113-121

5. Ogawa T, Koseki T (1989) Effect of composition profiles on metallurgy and corrosion behavior of duplex stainless steel weld metals. Weld Res Suppl:181-191

6. Westin EM, Hertzman S (2014) Element distribution in lean duplex stainless steel welds. Weld. World 58:143-160

7. Varol I, Lippold JC, Baeslack WA (1992) Welding of duplex stainless steels. Key Eng Mater 69-70:217-252

8. Valiente Bermejo, M.A.; Eyzop, D.; Karlsson, L.; Svensson, L.E.; Hurtig, K. Influence of multi-pass welding on the microstructure and properties of superduplex stainless steels. IIW Doc IX-2607-17 / IX-H-844-17; 2017;

9. Ramirez AJ, Lippold JC, Brandi SD (2003) The relationship between chromium nitride and secondary austenite precipitation in duplex stainless steels. Metall Mater Trans A 34A:1575-1597

10. Garzón CM, Ramirez AJ (2006) Growth kinetics of secondary austenite in the welding microstructure of a UNS S32304 duplex stainless steel. Acta Mater 54:3321-3331

11. Hosseini VA, Hurtig K, Karlsson L (2017) Effect of multipass TIG welding on the corrosion resistance and microstructure of a super duplex stainless steel. Mater Corros 68:405-415

12. Karlsson L (2012) Welding duplex stainless steels - a review of current recommendations. Weld. World 56:65-76

13. Nilsson J-O, Karlsson L, Andersson J-O (1995) Secondary austenite for mation and its relation to pitting corrosion in duplex stainless steel weld metal. Mater Sci Technol 11:276-283

14. Karlsson L (1999) Intermetallic phase precipitation in duplex stainless steels and weld metals: metallurgy, influence on properties and welding aspects. Weld World 43:1-23

15. Zhang Z, Jing H, Xu L, Han Y, Zhao L (2016) Investigation on microstructure evolution and properties of duplex stainless steel joint multi-pass welded by using different methods. Mater Des 109:670-685

16. Llorca-Isern N, López-Luque H, López-Jiménez I, Biezma MV (2016) Identification of sigma and chi phases in duplex stainless steels. Mater Charact 112:20-29 
17. Hsieh C-C, Wu W (2012) Overview of intermetallic sigma () phase precipitation in stainless steels. ISRN Metall 2012:1-16

18. Kasper J (1954) The ordering of atoms in the chi-phase of the ironchromium-molybdenum system. Acta Metall 2:456-461

19. Nilsson J-O, Liu P (1991) Aging at $400-600^{\circ} \mathrm{C}$ of submerged arc welds of $22 \mathrm{Cr}-3 \mathrm{Mo}-8 \mathrm{Ni}$ duplex stainless steel and its effect on toughness and microstructure. Mater Sci Technol 7:853-862

20. Lee B-C, Oh E-J, Kang C-Y (2014) Effect of R phase on the pitting corrosion in super duplex stainless steel. Korean J Mater Res 24: 610-616

21. Karlsson L, Pak S (1995) Influence of intermetallic phases on the corrosion properties of duplex stainless steel weld metals. Weld Int 9:554-562

22. Nilsson J-O (1992) Super duplex stainless steels. Mater Sci Technol 8:685-700

23. Pettersson N, Pettersson RFA, Wessman S (2015) Precipitation of chromium nitrides in the super duplex stainless steel 2507. Metall Mater Trans A 46:1062-1072

24. Zhang Z, Jing H, Xu L, Han Y, Zhao L (2017) The influence of microstructural evolution on selective corrosion in duplex stainless steel flux-cored arc welded joints. Corros Sci 120:194-210

25. Cortie, M.B.; Pollak, H. Embrittlement and aging at $475^{\circ} \mathrm{C}$ in an experimental ferritic stainless steel containing $38 \mathrm{wt} \%$ chromium. Mater. Sci. Eng. A 1995, 199, 153-163

26. Örnek C, Burke MG, Hashimoto T, Engelberg DL (2017) 748 K $\left(475^{\circ} \mathrm{C}\right)$ Embrittlement of duplex stainless steel: effect on microstructure and fracture behavior. Metall Mater Trans A Phys Metall Mater Sci 48:1653-1665

27. Sahu JK, Krupp U, Ghosh RN, Christ H-J (2009) Effect of $475^{\circ} \mathrm{C}$ embrittlement on the mechanical properties of duplex stainless steel. Mater Sci Eng A 508:1-14

28. Ferguson D, Chen W, Bonesteel T, Vosburgh J (2009) A look at physical simulation of metallurgical processes, past, present and future. Mater Sci Eng A 499:329-332

29. Hosseini VA, Karlsson L, Hurtig K, Choquet I, Engelberg D, Roy MJ, Kumara C (2017) A novel arc heat treatment technique for producing graded microstructures through controlled temperature gradients. Mater Des 121:11-23

30. Hosseini VA, Karlsson L, Engelberg D, Wessman S (2018) Timetemperature-precipitation and property diagrams for super duplex stainless steel weld metals. Weld World 62:517-533
31. Hosseini VA, Karlsson L, Örnek C, Reccagni P, Wessman S, Engelberg D (2018) Microstructure and functionality of a uniquely graded super duplex stainless steel designed by a novel arc heat treatment method. Mater Charact 139:390-400

32. Hosseini VA, Thuvander M, Wessman S, Karlsson L (2018) Spinodal decomposition in functionally graded super duplex stainless steel and weld metal. Metall Mater Trans A 49:2803-2816

33. ASTM (2002) International ASTM E562-11: standard test method for determining volume fraction by systematic manual point count. Beuth Verlag, Berlin ISBN 5957529001

34. Putz A, Althuber M, Zelić A, Westin EM, Willidal T, Enzinger N (2018) Methods for measurement of ferrite content in multi-pass duplex stainless steel welds. Weld World 63:1075-1086

35. ASTM International ASTM (2015) A262-15: standard practices for detecting susceptibility to intergranular attack in austenitic stainless steels. Berlin, Beuth Verlag

36. EN ISO 6507-1:2016 Metallische Werkstoffe - Härteprüfung nach Vickers 2016, 1-26

37. Operating Manual Feritscope ${ }^{\circledR}$ mp30. 2001, 30, 1-212

38. Escriba DM, Materna-Morris E, Plaut RL, Padilha AF (2009) Chiphase precipitation in a duplex stainless steel. Mater Charact 60: 1214-1219

39. Hosseini VA, Hurtig K, Eyzop D, Östberg A, Janiak P, Karlsson L (2018) Ferrite content measurement in super duplex stainless steel welds. Weld. World:551-563

40. Westin EM (2010) Pitting corrosion resistance of GTA welded lean duplex stainless steel. Weld. World 54:308-321

41. Pohl M, Storz O, Glogowski T (2007) Effect of intermetallic precipitations on the properties of duplex stainless steel. Mater Charact 58:65-71

42. Topolska S, Labanowski J (2009) Effect of microstructure on impact toughness of duplex and superduplex stainless steels. J Achiev Mater Manuf Eng 36(2):142-149

43. ASTM International ASTM (2012) G48: pitting and crevice corrosion resistance of stainless steels and related alloys by use of ferric chloride solution 1. Berlin, Beuth Verlag

Publisher's note Springer Nature remains neutral with regard to jurisdictional claims in published maps and institutional affiliations. 